long-felt want of a good and cheap blue colouring matter, was at first kept secret, till the process of preparation was published in a paper in the Philosophical Transactions, 1724 , by Woodward. Afterwards a number of chemists attempted to ascertain the true nature of the colouring matter, but without any further success than that improvements were made in the process of preparation, and some new substances were discovered, into the composition of which the colouring principle entered as a constituentamong which as the most important may be named the yellow prussiate of potash discovered by Macquer in 1752 . In 1772 Sage still believed that phosphoric acid entered as a constituent into the composition of prussiate of potash, and in 1786 Westrumb declared the colouring matter to consist of a volatile phosphor-soap. Two short papers by Scheele, together occupying not more that twenty-two pages of the Transactions of the Swedish Academy of Sciences for $I 782$ and $I 783$, at last brought clearness into this confusion. Scheele showed that the origin of the colouring power was a peculiar volatile acid (blue acid), whose properties he accurately ascertained, and of which he produced many new and important compounds. Scheele, besides, showed that the acid contained carbon and nitrogen, and that when subjected to combustion it gives off carbonic acid, and to dry distillation ammoniacal salts among others. On the other band, Scheele is thought not to have suspected that the substance which, without any special precautions, he produced in considerable quantity, smelled and tasted, forms one of the most powerful poisons with which we are acquainted. The work thus begun by Scheele was carried on by later chemists (Porret, Gay-Lussac, Berzelius, Faraday, Gmelin, Wöhler, Liebig, \&c.), and it is perhaps not too much to say that the accurate knowlodge we have thus obtained of the nature of the compounds of cyanogen has exerted an influence on the development of chemistry only inferior in importance to that of the discovery of oxygen and chlorine.

We find the first printed work of Scheele in the Transactions of the Swedish Academy of Sciences for $177 \mathrm{I}$. It bears the title, "On Fluor Spar and its Acid." Among the treasures which Pompey brought with him to Rome after his victory over Mithridates are enumerated goblets and cups of a beautifully-coloured fragile mineral, which, from the town at the plundering of which they were first obtained, were named Vasa myrrhina. They soon became fashionable, and Pliny and other writers speak of the fabulous sunis that were paid and the bloody deeds that were done in order to obtain them. Among all the different objects belonging to Ancient Rome preserved in our museums, there is not, remarkably enough, a single fragment of these vessels so renowned in the history of luxury but it has been guessed that they were made of a mineral which is now called fluor spar, and is still occasionally used for vases and cups. In mineralogical literature proper this mineral is first mentioned by the Saxon Agricola, who speaks of its use as a flux in the smelting of metals, and warns against mistaking this beautifully-coloured, but brittle and by no means hard mineral for a precious stone. Somewhat more than a century afterwards the art of etching on glass by means of this mineral was discovered at Nürnberg; and about the same time Elsholz, a Berlin physician who employed himself in the examination of phosphorescent substances, discovered that fluor spar became self-luminous when heated. All substances that are self-luminous without sensible combustion attracted at that period immense attention-certainly a survival from the alchemists' dreams about the philosopher's stone, which, among its other perfections, was also to have that of being self-luminous. The mineral, in consequence of its property of being a "light-bearer," now became the object of repeated but rather resultless examinations, until Scheele, by some simple experiments both analytic and synthetic, showed that the mysterious substance consisted of "lime saturated with a peculiar acid." This acid attacks glass and dissolves with ease siliceous substances. Scheele at first employed glass-vessels in producing it, which gave occasion to erroneous statements. The mistakes were immediately acknowledged and corrected when Scheele's attention was drawn to them by the apothecary Meyer of Stettin. Unwarranted objections, for instance by the Frenchman Boulanger, who declared that fluoric acid was nothing else than muriatic acid combined with some earth, and by Monnet, who believed that fluoric acid was only vitriolic acid "volatilised by means of a singular combination with fluor spar," were on the other hand refuted by new experiments in a paper printed in the Transactions of the Swedish Academy of Sciences for 1780. Scheele's examination of fluor spar had as its direct result the discovery of the simple substance fluorine, which without doubt, through its general occurrence in nature, and its properties differing from those of all other simple substances, is destined to play a very important part in the development of chemistry, although our knowledge of it is yet very incomplete from the impossibility of procuring vessels capable of resisting its corroding action.

( $T o$ be continued.) \section{ON THE LONG PERIOD INEQUALITY IN
RAINFALL}

I. $\mathrm{F}$ it be true that there is a variation in the power of the sun depending on the state of his surface, this variation might naturally be expected to make itself apparent through a corresponding change in the rainfall of the earth, so that when the sun is most powerful there ought to be the greatest rainfall.

2. While the connection indicated above is that which most readily occurs to the mind, yet the difficulty of ascertaining the facts of the case in a manner bearing the smallest approach to completeness, is so great as to be at present insuperable.

There is, first of all, an intense reference to locality in rainfall, so that the rainfall at one place may differ greatly from that at another place in its near neighbourhood.

Again, there are, probably, in addition to possible secular inequalities, very great oscillations in the yearly rainfall at any one place, or accidental variations as we may term them, in our ignorance of their cause.

Thirdly, it is in comparatively few places, and those places chosen not with the smallest reference to this particular problem, that we have anything like a trustworthy account of the rainfall throughout a considerable number of years.

Fourthly, we have no information of any importance with respect to the rainfall at sea.

3. Besides the formidable catalogue of difficulties now mentioned, we ought to bear in mind the following considerations. The convection currents of the earth are regulated by two things, one of which is constant, while the other may be variable. The constant element is the velocity of rotation of the earth on its axis, while the element of possible variability is the power of the sun. Hence it follows that if the sun be variable. it will cause a variation in the direction as well as in the intensity of the earth's convection-currents on the principle which tells us that the resultant of two forces, one constant and the other variable, must vary both in magnitude and direction.

Now if it be true that we have a long period variation, not merely of the intensity, but also of the distribution of the earth's convection-currents, and if we bear in mind the intensely local reference in rainfall, it would be too much to expect that the rainfall inequality should exhibit the same years of maximum and minimum at all places.

${ }^{\mathbf{I}}$ By Balfour Stewart, LL.D., F.R.S., Professor of Natural Philosophy at the Owens College, Manchester. Being 2 paper read before the Lit. and Phil. Society of Manchester. 
It is even conceivable that some places might exhibit a maximum when others showed a minimum, while others again might exhibit a double instead of a single period.

4. It appears to me that if we bear in mind these considerations, it will not answer to add together the rainfalls of a few selected stations as they stand, with the view of determining by this means whether there be a long-period inequality in the rainfall of the whole earth. We are not yet in a position to reply experimentally to this question.

It does not, however, follow that nothing can be done. Dr. Meldrum and others appear to have achieved good preliminary work in the direction of indicating the existence of a rainfall inequality depending upon the state of the sun. Dr. Meldrum began by pointing out that in a good many places there is a greater rainfall during years of maximum than during years of minimum sunspots, and that this phenomenon repeats itself from one solar cycle to another. Again, Governor Rawson has pointed out the existence of certain localities where the rainfall inequality appears to be of a precisely opposite character, while Dr. Hunter has shown the practical importance of the investigation with reference to certain tropical stations. The subject has likewise been discussed by Piazzi Smytb, Stone, and others.

5. The question has arisen whether it might be possible to throw any light on this problem by the method of deducing unknown inequalities proposed by Mr. Dodgson and myself (see Proceedings of the Royal Society, May 29, 1879). The essence of this method consists in a way by which we may numerically estimate the indications of an equality. Let us suppose, for instance, that in ignorance of the diurnal range of temperature we try to find whether there be a temperature inequality of twenty-four hours, or whether there be not rather one of twenty-six hours. We should begin by taking a large number of hourly readings of temperature, and we should group these into two series, the one containing twenty-four numbers in each horizontal row, and the other twenty-six. We should thus have twenty-four vertical columns from the one series and twenty-six from the other, and we should take the mean of each vertical column of each series, as well as the mean of the whole. Now it would speedily be found that an inequality was indicated by the twenty-four hourly series, and none by the twenty-six hourly series. For in the first series the mean of that vertical column representing observations at $5 \mathrm{~A}$.M. would be greatly less than the mean of the whole, while the mean of that column representing observations at 2 P.M. would be much higher than the mean of the whole. On the other hand, in the twenty-six hourly series, provided it were sufficiently extended, we should perceive no such differences. Thus, in the twenty-four hourly series the differences of the means of the various vertical columns from the mean of the whole would be much greater than in the twenty-six hourly series, and the mean amount of these differences might be taken to form a numerical criterion of the presence or absence of an inequality.

6. This method applied to the subject in hand might be expected to reveal the presence or absence of inequalities in rainfall, provided we have observations sufficient for the purpose. It is clear that the successful application of this method does not require a previous knowledge of the exact form of the inequality. Whether a maximum rainfall occur at epochs of maximum or at epochs of minimum sun-spot frequency, whether there be only one rainfall maximum corresponding to the solar period, or two, or even three, is a matter of no consequence as far as this method is concerned. All that is necessary is that the rainfall should always be similarly affected by similar states of the sun.

Here, however, we must bear in mind that this method of detecting inequalities by summing up and averaging the departures from the mean caused by the inequality, likewise sums up and averages the accidental fluctuations. Now these accidental fluctuations are particularly large for rainfall, and it is therefore desirable to lessen their disturbing effect as much as possible. This can only be done by confining ourselves to long series of observations in which the accidental fluctuations may be supposed to counteract each other to a great extent, while the long period fluctuations will remain behind.

7. Through the kindness of Mr. Whipple, Director of the Kew Observatory, I have received copies of those catalogues of rainfall which he has himself made use of in a paper which was recently communicated to the Royal Society (January 8, I880). Of these Paris, Padua, England, and Milan form the most extensive series, that of Paris embracing 16r years, Padua, I54, England (Symons's table), 140, Milan, I I5. Mr. Whipple has likewise furnished materials by which the labour of applying the process in hand to these series will be greatly abridged, and he has kindly allowed me to make use of these. I will therefore apply the process to these four stations.

8. Let us begin by grouping the Paris yearly values into series of 8 . We thus obtain the following final numbers (in centimetres):-

$$
5^{1} 4,47^{\circ} 5,45^{\circ} 7,48 \cdot 7,5 \mathrm{I} \cdot \mathrm{r}, 49^{\circ} 8,46^{\circ} 5,47^{\circ} \text {, }
$$

the mean being $48 \cdot 5$. From this we obtain the following series of differences:-

$$
+2 \cdot 9-10-2 \cdot 8+0 \cdot 2+2 \cdot 6+I^{\prime} 3-2 \cdot 0-I^{\prime} 3 .
$$

In order to diminish the effect of accidental fluctuations, let us equalise this series of differences by taking the mean of each two. We thus obtain

$$
+0.8+\mathrm{I} \cdot 0-\mathrm{I} \cdot 9-\mathrm{I}_{3}+\mathrm{I}_{4} 4+\mathrm{I} \cdot 9-0.4-\mathrm{I} 7 .
$$

If we now add these together, without respect of sign, and divide by their number (8), we obtain I' 3 as the mean departure from the mean of the whole, and bringing this departure into a proportional shape by dividing it by the mean rainfall, we obtain $\frac{I^{\circ} 30}{48 \cdot 5}=2.68$ per cent.

9. These explanations will enable the reader at once to

\begin{tabular}{|c|c|c|c|c|c|c|c|}
\hline Name of & & rtional & ainfall i & quality & s exhibi & ed by se & es of \\
\hline $\begin{array}{l}\text { station. } \\
\text { English }\end{array}$ & 8 yrs. & 9 yrs. & Io yrs. & in yrs. & 12 yrs. & I3 yrs. & $x_{4} \mathrm{yrs}^{2}$ \\
\hline $8 x$ & $2 \cdot 63$ & 2.14 & $x \cdot 55$ & $1 \cdot 79$ & $3: 15$ & $1 \cdot 69$ & $2 \cdot 57$ \\
\hline ris . & $2 \cdot 68$ & 3.07 & $\mathbf{r} 99$ & $2 \cdot 65$ & 370 & $2 \cdot 57$ & $3^{\circ} 08$ \\
\hline adua.. & $\mathbf{I}^{\circ} 77$ & $3 \cdot 62$ & 2.02 & $x \cdot 47$ & $3^{\circ} 3^{1}$ & $3 \cdot 52$ & 340 \\
\hline Ailan .. & $\mathrm{I} 12$ & $3 \cdot 22$ & $3 \cdot 16$ & $1 * 78$ & 413 & $3 * 78$ & 2.49 \\
\hline
\end{tabular}
perceive the principle of construction of the following table :-

We ought to give the English, the Paris, and the Padua observations a somewhat higher weight than those of Milan, as the former embrace a longer period. This will be done sufficiently well by giving the first three sets weights of 3 each and the Milan set a weight of 2 . If we perform this operation, and then take the mean of these stations, we obtain as under :-

\section{Mean of \\ $\left.\begin{array}{c}\text { the four } \\ \text { stations } \\ \text { weighted }\end{array}\right\} \begin{array}{lllllll}2.15 & 3.00 & 2.09 & 1.94 & 3.52 & 2.81 & 2.92\end{array}$ as above} Proportional rainfall inequality as exhibited by series of
8 yrs.

A maximum corresponding to nine years and a still greater one corresponding to twelve years is thus exhibited, each of these being recorded at three stations out of four.

The proportional numbers indicated are not large, but it must be remembered that it is the mean difference for all the years that is given, and that the maximum and minimum rainfall will represent differences above and 
below the mean which will each be about double of the numbers recorded above.

10. Regarding the rainfall values as representing the meteorological result of the sun's action, let us now compare these with declination range values, which may be taken to represent the sun's magnetic effect. Prof. Loomis has compiled (American Journal of Science and Arts, second series, vol. l. p. 153) what seems to be a very good table, exhibiting a set of yearly values of magnetic declination range, extending with slight breaks from 1777 to 1868 .

Let us take this table, and treat it precisely as we have treated the rainfall, except that it does not seem necessary to make any attempt at equalisation, such as that made in Art. 8.

We thus obtain the following result :-

Name of Proportional declination range inequality as exhibited by series of

station. 8 yrs. 9 yrs. Io yrs. II yrs. 12 yrs. 23 yrs. I4 yrs.

station.

Prague,

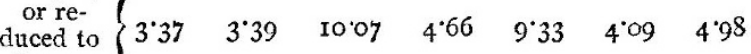

Prague

Here we have unmistakable maxima corresponding to ten and twelve years. The result is thus not unlike that which we have derived from rainfall observations ; indeed we could hardly expect a more perfect correspondence between the two, bearing in mind the limited amount of observations which we have for determining inequalities of long periods.

\section{DEEP-SEA DREDGING AND LIFE IN THE $D E E P S E A^{\mathrm{x}}$}

$A S$ Dr. Carpenter explained in his lecture here some short time ago, four-elevenths, or nearly threefourths of the surface of the earth is covered by sea. The average depth of the ocean is, according to the latest calculations of Mr. Otto Krummell, about I,877 fathoms, or somewhat over two miles, very nearly the distance from the Royal Institution to the top of Primrose Hill. If we try and project Primrose Hill directly under our feet, keeping the distance the same, we shall form a conception of the mean depth of the sea. The greatest depth known to exist was discovered by the United States ship Tuscarora near the Kurile Islands, in the North-east Pacific. It is 4,655 fathoms, or about five miles and a quarter.

The highest mountain existing is of about the same height as the deepest sea is deep. Mount Everest is 4,833 fathoms in height. So insignificant, however, is the total volume of the land raised above sea-level in proportion to the vast cavity occupied by the sea, that were this cavity emptied of its water, the whole of the land now above sea-level could be shorelled into it twenty-two and a half times over before it would be filled up to the present sea-level.

Nevertheless the depth of the oceans, great as it is, is as nothing in comparison with the vastness of their extent of surface. As Mr. Croll has said, the oceans in relation to their superficial area are as shallow as a sheet of water 100 yards in diameter and only an inch in depth.

The sides of the ocean-basins are not at all steep. They are mostly so little inclined that an ordinary locomotive engine could run up them in a straight line with ease. Their inclination is usually not more than three or four degrees or less. Around some oceanic islands the slope is greater. The steepest slope known is, as Capt. Tizard informs me, at Bermuda, where there is an inclination of nearly twenty degrees from the edge of the reef to 2,000 fathoms. There are no such things as mountains and valleys on the deep-sea bottom. Animals cannot slip down against their will into the depths, but must move

'Friday Evening Lecture delivered at the Royal Institution on March 5 , by H. N. Moseley, F.R.S., Assistant Registrar of the University of London. deliberately into them, and travel a long journey to reach them.

The pressure exerted by the superincumbent water at great depths is so great as to be almost beyond conception. It amounts roughly to a ton on the square inch for every $I, \infty 0$ fathoms of depth, about 166 times as much as the pressure to which we are subjected at the present moment. At the greatest depths the pressure is about four tons and a half. Vast though this pressure is, it is, however, only about one-eighth of that which Prof. Abel and Capt. Noble have measured, as produced in their experiments on gunpowder. The deep-sea animals, being completely permeated by fluids, are probably no more conscious of pressure acting upon them than we, and, so long as they move slowly from one depth to another, are most likely unaffected by the consequent changes of pressure.

With regard to the temperature of the deep-sea water, the conditions which would affect animals are comparatively simple. Nearly all over the ocean the temperature at 500 fathoms is as low as $40^{\circ} \mathrm{F}$., and this is the case even immediately under the equator in the Atlantic and Pacific Oceans. Below 2,000 fathoms the temperature is never more than a few degrees above freezing-point, excepting in the peculiar cases of land-locked seas, such as the Sulu Sea.

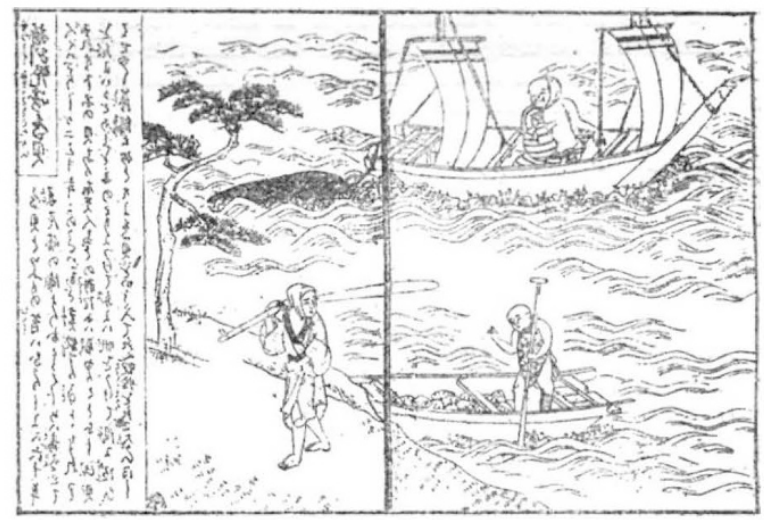

FIG. 1.-Japanese dredge in action.

At comparatively small depths in the sea it is almost certainly entirely dark so far as sunlight is concerned. Prof. Forel found that in the Lake of Geneva, even at a depth of only 30 fathoms, photographic paper was entirely unacted on after protracted exposure. We can hardly believe that the red, green, or yellow rays can penetrate sea-water much further than those to which ordinary photographic paper is sensitive. It may safely be assumed that sunlight is entirely absent at a depth of 200 fathoms, probably at a much less depth. We dredged blind crustacea at a depth of 120 fathoms, and a blind isopod is found in the Lake of Geneva at a depth of about 55 fathoms.

In depths of 500 fathoms almost everywhere, everywhere in over 1,000 fathoms, there must be an entire absence of any currents in the water. Any movement taking place in the water at that depth must be of a molecular nature only, excessively slow and quite imperceptible to animals.

Altogether the deep sea, cold, dark, and still, must b about the slowest place to live in that can be imagined.

I now turn to the consideration of deep-sea dredging.

The dredge is an ancient contrivance of fishermen of a very wide distribution. It is used in Japan, and the accompanying amusing figure (Fig. I) is taken from a woodcut in a Japanese book on the principal land and marine food products of Japan. In it a fisherman is 